My Personal Experiences in the Midst of Chaos Pyrros DG

Athens, Greece

The establishment of a United Nations Dispensary in three different war-torn countries-Afghanistan, Liberia, and Iraq-will be presented. The contingency plans for dealing with emergencies will be discussed and the problems of the implementation of these plans when chaos erupted abruptly will be analysed. For each of the following situations, the background as well as the medical problems arising from it will be reviewed:

1) The setting up of a small clinic at the bunker of the UN Guest House during a coup-d'etat attempt in Kabul, Afghanistan in 1990, as well as the evacuation of the UN offices using the UN Ambulance as the leading car of the convoy;

2) The establishment of a UN Dispensary in Monrovia, Liberia in 1991 following the complete destruction of the UN offices and a solution to the problem of properly tested blood for transfusion should the UN staff require it. The ways in which the results of this effort in 1991 helped deal with the eruption of hostilities in 1996 will be described;

3) The setting up of an annex to the established UN Dispensary of Baghdad, Iraq in 1997 and the Standard Operating Procedures for the aeromedical evacuation of sick UN personnel will be described using the example of a young Nepalese UN Security Guard who was evacuated from Kurdistan to Kuwait via Baghdad.

Final remarks will contain measures that are applicable to all emergency situations in the midst of chaos.

Key words: Afganistan; contingency plans; dispensaries; experiences; Iraq; Liberia; medical care during chaos; transfusions; United Nations

\section{Technical Devices and Systems for Telecommunication Rabtu $A$}

Telecom Finland Ltd, Rovaniemi, Finland

Telecommunications and the separate systems involved should be considered as a whole. Separate devices and features are meaningless if they are not related to a larger and better manageable whole. When we think of the communications chain from the point of view of its technical components, we can distinguish the systems used in the disaster freld from each other including the telecommunications connections and the centralized control of the activities.

In the disaster zone, information related to telecommunications connections should be obtained preferably automatically from several sources. Images to be transmitted include the vital parameters of the victims, environmental conditions, image transfer from the subjects, and voice transmission.

The unusual environmental conditions require much from the devices in use. They must be shock and water resistant, and must withstand extreme temperatures. The power supply as well, must be designed for a long period of activity. The devices also must be user-friendly, so that they can used quickly. In the disaster zone, telecommunications connections should be wireless, but also must have a flexible access to various ground networks so that communications can be easily established, e.g., to the control centre and to the hospital(s). Telecommunications can be arranged either as wireless, surface connections, or as satellite connections. There presently are several wireless networks in use (NMT450, NMT900, Mobinet, Mobitex, GSM, etc.), and the transfer speeds of the emerging networks will increase substantially in the future. Additionally, there also will be new networks in operation (e.g., Virve, UMTS).

Telecommunications with certain centralized operative sites and control centres and hospitals should be fully operational. These should be connected to some fixed, ground networks. Simultaneously, telecommunications in use also shall support mobile control centres.

The technology evolution has been strong in the telecommunications sector, and continues to forage in this manner. As technology evolves, new and currently unavailable features will be introduced. Clear trends include greater transfer speeds of wireless communications and wireless video image transfers. It is important for manufacturers that they comply with standards in order to achieve compatibility and inter-operability between multi-vendor pieces of equipment.

Key words: communication systems; control centres; devices; disasters; linkages; telecommunications

\section{Telecommunication in Chemical Disasters: Mastering the Situation \\ Rabtu $A$}

Telecom Finland Ltd, Rovaniemi, Finland

When a chemical accident occurs, besides the follow-up of the status of the victims, there must be follow-up of the environmental conditions and of the situations which may result from them. The control centre should have a versatile and continuously updated picture of the situation. To follow the situation, we not only need telephone communications, but also the transmission of telemetry and imaging information.

From the disaster zone, we need the transmission of information related to environmental conditions, like the strength and direction of wind, temperature, rain, etc. This information can be obtained with a mobile weather station fitted with telecommunication devices.

Today's technology makes it possible to transfer live: good quality images without the use of wires. Live pictures can be transmitted from different sources. The rescuers can have cameras fixed on their helmets, so that images can be transmitted to the control centre in real-time. In the disaster zone, there may be a moveable camera set up on a tripod that could be guided from the control centre using 